\title{
Identification and expression analysis of
}

CBF/DREB1 and COR15 genes in

mutants of Brassica oleracea var.

botrytis with enhanced proline

production and frost resistance

\section{Hadi, F}

http://hdl.handle.net/10026.1/1427

10.1016/j.plaphy.2011.08.013

Plant Physiology and Biochemistry

Elsevier BV

All content in PEARL is protected by copyright law. Author manuscripts are made available in accordance with publisher policies. Please cite only the published version using the details provided on the item record or document. In the absence of an open licence (e.g. Creative Commons), permissions for further reuse of content should be sought from the publisher or author. 
Provided for non-commercial research and education use. Not for reproduction, distribution or commercial use.

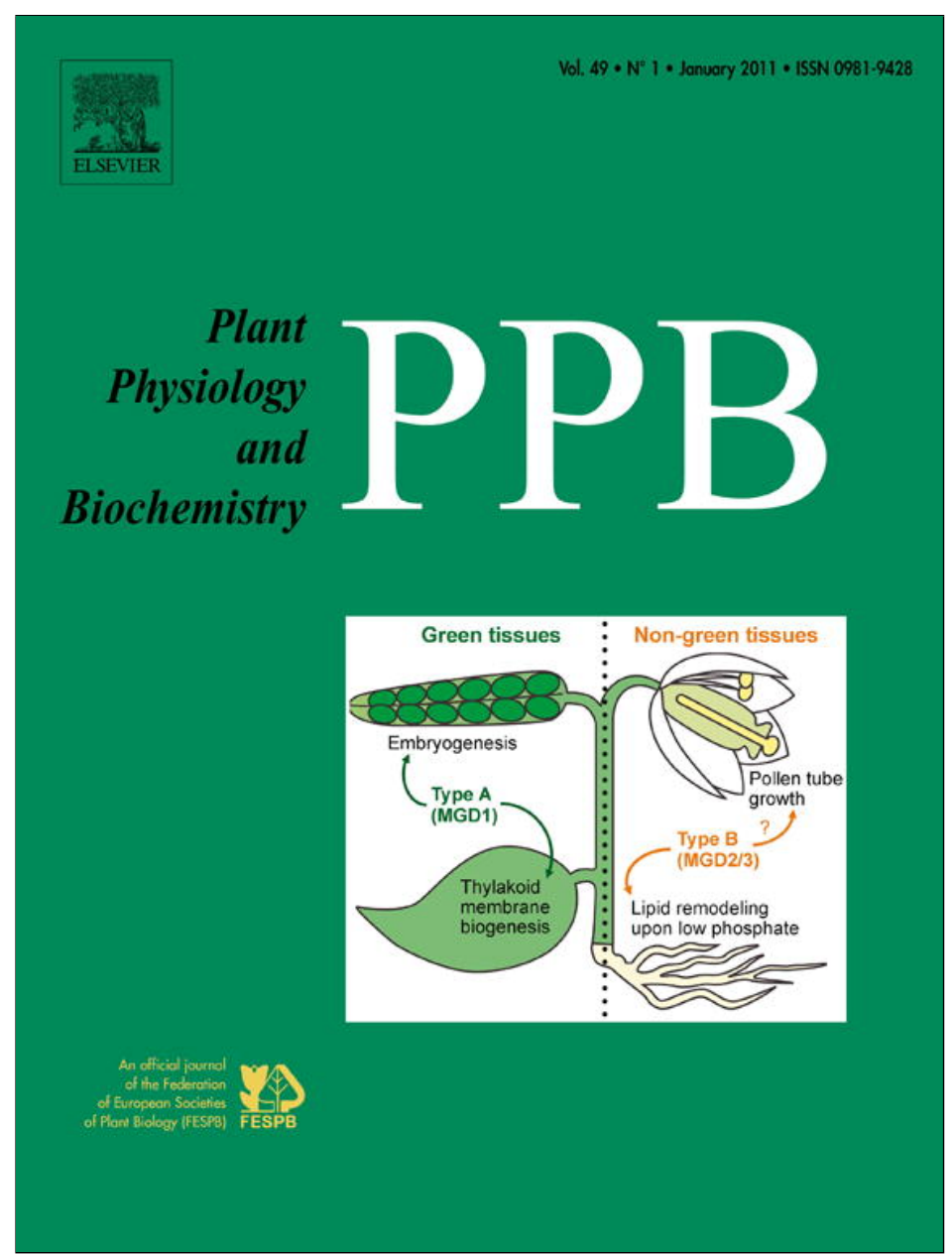

(This is a sample cover image for this issue. The actual cover is not yet available at this time.)

This article appeared in a journal published by Elsevier. The attached copy is furnished to the author for internal non-commercial research and education use, including for instruction at the authors institution and sharing with colleagues.

Other uses, including reproduction and distribution, or selling or licensing copies, or posting to personal, institutional or third party websites are prohibited.

In most cases authors are permitted to post their version of the article (e.g. in Word or Tex form) to their personal website or institutional repository. Authors requiring further information regarding Elsevier's archiving and manuscript policies are encouraged to visit:

http://www.elsevier.com/copyright 
Research article

\title{
Identification and expression analysis of CBF/DREB1 and COR15 genes in mutants of Brassica oleracea var. botrytis with enhanced proline production and frost resistance
}

\author{
Fazal Hadi ${ }^{\mathrm{a}, \mathrm{b}, *}$, Martyn Gilpin ${ }^{\mathrm{b}}$, Michael P. Fuller ${ }^{\mathrm{b}}$ \\ ${ }^{a}$ Department of Biotechnology, University of Malakand, KPK, Pakistan \\ ${ }^{\mathrm{b}}$ School of Biological Sciences, Faculty of Sciences, University of Plymouth, PL4 8AA, UK
}

\section{A R T I C L E I N F O}

\section{Article history:}

Received 27 May 2011

Accepted 28 August 2011

Available online 16 September 2011

\section{Keywords:}

Frost resistance

Cauliflower

CBF/DREB1

COR15

Cold acclimation

\begin{abstract}
A B S T R A C T
Frost resistant mutants of Brassica oleracea var. botrytis were investigated for the presence of CBF/DREB1 and COR15a gene products and induced frost resistance. Total RNA of clones was isolated after $3 \mathrm{~h}, 6 \mathrm{~h}, 24 \mathrm{~h}$ and $14 \mathrm{~d}$ acclimation at $4{ }^{\circ} \mathrm{C}$ and proteins and free proline were isolated after $14 \mathrm{~d}$ acclimation. CDNA was produced using RT-PCR and the first CBF gene in B. oleracea detected and did quantify. Through SDS-PAGE and Western blotting, the COR15a protein was detected for the first time in $B$. oleracea. The results confirmed the first report of the presence of BoCBF/DREB1 in B. oleracea and this only appeared under cold acclimation. The sequence analysis of predicted amino acids revealed a very high homology (90\%) with CBF sequences of other Brassica species (BNCBF5/DREB1, BrDREB1 and BjDREB1B) and homology reduced to $67 \%$ when compared to plants other than Brassicas. BoCBF/DREB1 transcript levels increased up to $24 \mathrm{~h}$ acclimation and then declined. Some mutants showed BoCBF/DREB1 expression at $3 \mathrm{~h}$ while others only after $6 \mathrm{~h}$ and $24 \mathrm{~h}$ acclimation. The genotypes showed positive significant correlation between BoCBF/DREB1 expression and frost resistance $\left(R^{2}=0.9343\right)$. The proline level under acclimation increased about 8 fold and demonstrated positive and significant correlation with BoCBF/DREB1 expression. Proline also showed positive and significant correlation with frost resistance under cold acclimation but very not under nonacclimation. All clones were positive for COR15a protein after $14 \mathrm{~d}$ cold acclimation and expression correlated with frost resistance. Under non-acclimation COR15a was constitutively expressed in 3 mutants.
\end{abstract} (C) 2011 Elsevier Masson SAS. All rights reserved.

\section{Introduction}

Frost, drought and salt are environmental stresses that have major limitations for plant growth and crop productivity globally. In the case of economically important plants, frost can cause significant losses to crop production. The major damaging effect of freezing is that it induces acute cellular dehydration and eventually severe cell membrane damage [1]. Many plants on exposure to non-freezing low temperatures increase their freezing tolerance, a process known as cold acclimation [2]. Explanation of the mechanisms of acclimation and the development of freezing tolerance is of vital importance for the design of novel crop varieties to allow the use of marginal lands for agricultural production. A concerted effort through physiology, molecular biology and biochemistry is required to understand the complex quantitative trait of low temperature and freezing tolerance

\footnotetext{
* Corresponding author. Room No. 317, Davy Building, School of Biological Sciences, University of Plymouth, Plymouth, Devon PL4 8AA, UK. Tel.: +44 (0) 7888002404, +92 (0) 3476873779 .

E-mail addresses: fazalbiotech@yahoo.com, fhadi@uom.edu.pk (F. Hadi).
}

[3]. Cold acclimation plays an important role in membrane freezing tolerance as shown by early research that cold-acclimated cabbage and spinach synthesized proteins that protected thylakoid membranes against freeze damage and the cryoprotective activity of these proteins was 10,000 times higher than sucrose in protecting against freeze-thaw damage [4]. Analysis of gene expression in plants during cold acclimation has revealed the existence of low temperature responsive genes with complex regulatory mechanisms, pathways and products that assist plant cells to resist and survive freezing [5]. Several of the low temperature responsive genes contain in their promoter regions one or more copies of a cis element C-repeat/low temperature responsive element/dehydration responsive element (CRT/LTRE/DRE) [6] with a conserved core sequence of CCGAC, which is the binding site for the cold specific transcriptional activators CBFs/DREBs [7] that induce the expression of cold responsive (COR) genes which subsequently enhance cold/frost resistance in plants [3]. The CBF/DREB proteins are characterized by an AP2 (Apetala2) domain and the CBF signature motif DSAWR [8].

In many higher plants the existence of a transcription factor ICE (Inducer of CBF expression), acts at the promoter of CBF/DREB 
(C-repeat/dehydration responsive element binding factor) genes upon cold acclimation. The ICE stimulates the transcription of $C B F /$ $D R E B$ genes followed by induction of the CBF regulon, a set of coexpressed genes that share a similar expression profile across multiple temporal, spatial, genetic and environmental conditions and under the common transcriptional regulations [9,10]. Even though the whole cold induced regulon is still not well understood, various specific profiles of gene expression have been observed during cold acclimation [11] and the expression of COR15 protein is used to indicate the up-regulation of the cold induced regulon.

Physiologically, cell membranes and other important macromolecules need to be protected during freezing induced dehydration and compatible solutes and sugars can provide important osmoregulatory protection. Proline is considered to be an important compatible solute and this amino acid could be a part of the adaptation mechanism to several abiotic stresses [12]. Proline accumulation under stress was reported for the first time in plant tissues of rye grass [13] and subsequently this has been shown to be a common phenomenon of plants on exposure to cold acclimation [14]. Proline, COR proteins, and sugar biosynthesis are regulated co-ordinately and the $C B F$ gene plays an essential role in this regulation [15].

Cauliflower (Brassica oleracea var. botrytis) is one of the most popular vegetable crops worldwide and originated in the temperate Mediterranean coastal area where it gets exposed to freezing temperatures [16,17]. Cauliflower is grown for its white curd, which consists of inflorescence and floral meristems. It is a low-calorie vegetable, a rich source of vitamins $\mathrm{C}, \mathrm{K}$, and $\mathrm{A}$ (beta-carotene), folic acid, fiber, and flavonoids which give the cauliflower antiinflammatory and antioxidant proprieties [18]. Cauliflower is a potentially cancer preventative vegetable [19]. It is also a carbohydrate source that could be an efficient fuel for energy production [20]. Cauliflower belongs to the highly phenotypically diverse species $B$. oleracea which also includes Broccoli, Cabbage, Brussel Sprouts, Kale and Kohl rabi. B. oleracea is one of the diploid cornerstones of the Brassica triangle [21]. Presently, the molecular mechanism by which the cauliflower perceives and tolerate freezing is poorly understood. Through chemical mutagenesis the cauliflower mutants were produced using $\mathrm{N}$-nitroso-N-ethyleurea (NEU) and N-nitroso-Nmethylurea (NMU) followed by selection in the presence of hydroxyproline [22]. These mutants and control clones were maintained under the in-vitro condition for three years by continuous subculturing after each 3-4 months. These clones were reassessed and some of these mutants were shown to be proline over-accumulators and were variously more resistant to frost, salt or drought or combinations of these stresses [23]. However the molecular bases of these resistances have not hitherto been determined in cauliflower.

In previous investigation on these mutants [23] the symbol ' $\mathrm{S}$ ' had been used for mutants, while in the present investigation these mutants were regenerated and then indicated by symbol ' $\mathrm{K}$ ' throughout this paper. In this paper we report the investigation to determine whether CBF/DREB1 and COR15 genes from these cauliflower mutants show any variation in expression and whether or not such variation is correlated with the expression of frost resistance and the level of proline. Since the presence of CBF/DREB1 and COR15 genes in cauliflower have not yet been reported in the literature it was necessary firstly to determine whether these genes were present in cauliflower.

\section{Results}

\subsection{Frost resistance analysis of the clones (mutants and control)}

The electrolytes leakage increased with lowering the temperature (Fig. 1A-D). Non-freezing $+1{ }^{\circ} \mathrm{C}$ temperature was used to compare with the effect of freezing temperature at $-2{ }^{\circ} \mathrm{C},-4{ }^{\circ} \mathrm{C}$
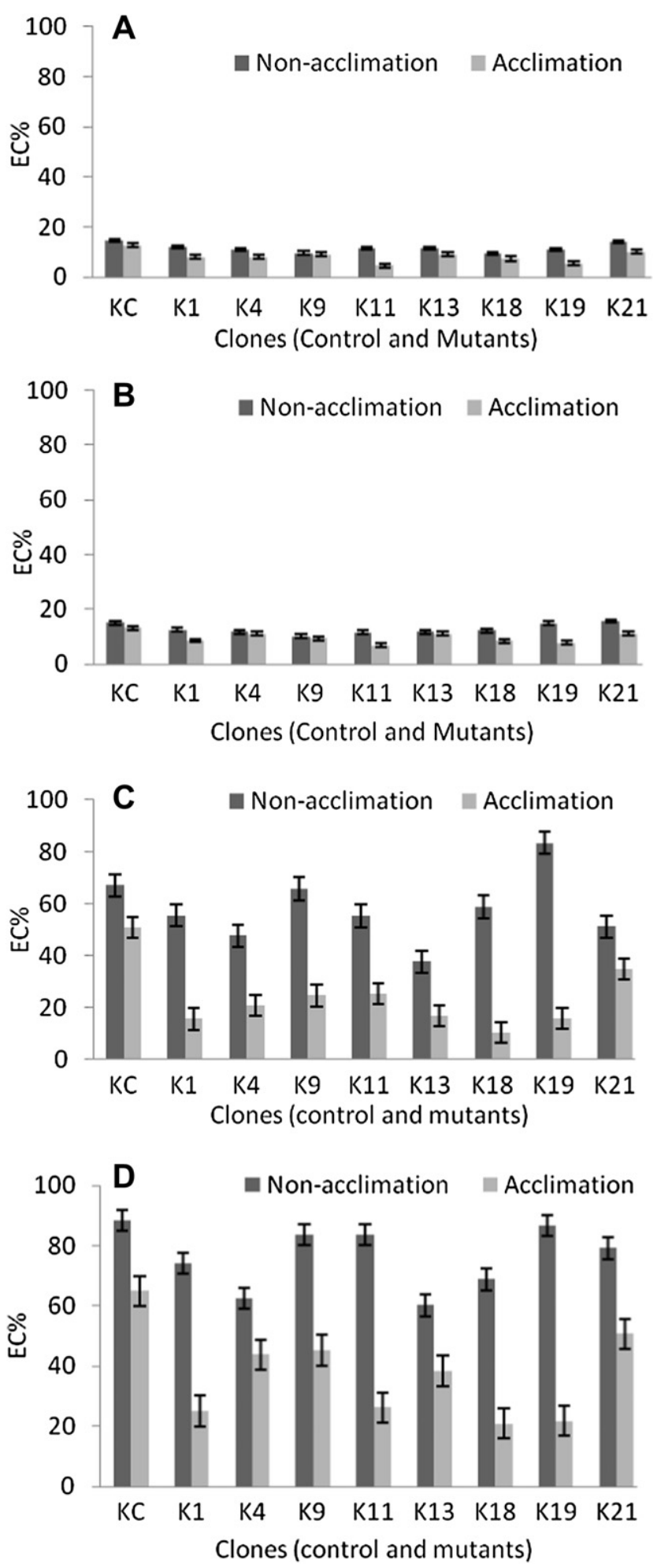

Fig. 1. Frost damage (Electrical conductivity EC\%) of cauliflower clones at $+1{ }^{\circ} \mathrm{C}$ (A), $-2{ }^{\circ} \mathrm{C}(\mathrm{B}),-4{ }^{\circ} \mathrm{C}(\mathrm{C})$ and $-6{ }^{\circ} \mathrm{C}(\mathrm{D})$. $\mathrm{KC}$ is control and $\mathrm{K} 1-\mathrm{K} 21$ are mutant clones. The bars indicate standard error of the mean values of replicates.

and $-6{ }^{\circ} \mathrm{C}$. But at $+1{ }^{\circ} \mathrm{C}$ and $-2{ }^{\circ} \mathrm{C}$ showed almost similar effect and no clear difference was observed as shown in Fig. $1 \mathrm{~A}$ and $\mathrm{B}$. The leakage of electrolytes from cells sharply increased at $-4{ }^{\circ} \mathrm{C}$ (Fig. 1C) and the highest damage in terms of highest relative electrical conductivity (REC) was observed at $-6{ }^{\circ} \mathrm{C}$ as shown in Fig. 1D. 
The acclimation process was found to be very effective in increasing frost resistance but was more effective in the mutant genotypes. Clear differences existed among acclimated mutants at $-6{ }^{\circ} \mathrm{C}$ with some mutants like $\mathrm{K} 1, \mathrm{~K} 11, \mathrm{~K} 18$, and $\mathrm{K} 19$ showing high resistance where the EC\% was less than $40 \%$ whilst the mutants $\mathrm{K} 4$, K9, K13, and K21 showed moderate resistance as compared to the control (Fig. 1D).

\subsection{Expression analysis of BoCBF/DREB1}

The $C B F / D R E B 1$ gene sequence of $B$. oleracea var. botrytis was identified and designated as BoCBF1/DREB1. The PCR product of cDNA and genomic DNA showed similar fragment sizes assuming that the isolated sequence is an exon (Fig. 2A-E). Among the mutants there were apparent differences in expression level observed under cold acclimation. Such as after $3 \mathrm{~h}$ cold acclimation only K1, K11, K13, K18 and K19 (represented by lane 1, 4, 5, 6, 7 respectively in Fig. 2A) showed RT-PCR product. After $6 \mathrm{~h}$ acclimation, two more clones K21 and KC (lane 8 and 9 in Fig. 2B) also showed the product. After $24 \mathrm{~h}$ acclimation the clones showed maximum product of RT-PCR (Fig. 2C) whilst after $14 \mathrm{~d}$ cold acclimation, only very weak bands were present (Fig. 2D) indicating that the transcript level had declined. Similar and optimized RT-PCR reactions were made for both of acclimated and non-acclimated clones. But all the mutants and control clones under non-acclimation condition showed no RT-PCR product as shown in Fig. 2F.

\subsection{Sequence analysis}

The cDNA sequence and the amino acid sequence of the predicted protein encoded by the isolated BoCBF1/DREB1 was subjected to multiple sequence alignment using clustalW2 EMBL-EBI [24]. The cDNA sequence (Fig. $3 A$ ) and the amino acids sequence (Fig. 3B) of the isolated BoCBF1/DREB1 gene posses all the important structural domains and regions that distinguish $\mathrm{CBF}$ such as the highly conserved AP2 domain and the CBF signature motif 'DSAWR' immediately downstream of the AP2 domain (Fig. 3B). The AP2 domain has been suggested to play a crucial role in recognition of the DNA binding sequence in the promoter of cold responsive genes [25]. The alignment of BoCBF1/DREB1 with cold induced CBF's of Brassica species Brassica napus (GeneBank, AAM18958), Brassica juncea (ABX00639), and Brassica rapa (ACL12046) showed 90\% sequence homology (Fig. 3B). But when the BoCBF1/DREB1 amino acids sequence was compared in a broad way with members of the Brassicaceae family other than Brassicas, then the consensus reduced to $67 \%$ as shown in Fig. 3C. These findings indicate that the sequence isolated here from $B$. oleracea var. botrytis is more highly conserved in Brassica species than in the other members of Brassicaceae family but homology with other members was still high.

\subsection{Correlation between $C B F$ expression and frost resistance in clones (mutants and control)}

There was a positive correlation between frost resistance and apparent CBF expression, with increased CBF expression associated with decreased \% relative electrical conductivity. This correlation was significant after $14 \mathrm{~d}$ (Fig. 4A) and after $24 \mathrm{~h}$ (Fig. 4B) cold acclimation, but after $6 \mathrm{~h}$ (Fig. 4C) and $3 \mathrm{~h}$ (Fig. 4D) cold acclimation the correlation was also positive but not statistically significant. The highest association was found between $\mathrm{CBF}$ expression at $14 \mathrm{~d}$ and EC\% at $-6{ }^{\circ} \mathrm{C}\left(R^{2}=93.43 \%\right)$ and the second highest between $\mathrm{CBF}$ expression at $24 \mathrm{~h}$ and $\mathrm{EC} \%$ at $-6{ }^{\circ} \mathrm{C}\left(R^{2}=82.57 \%\right)$.
A $3 \mathrm{~h}$

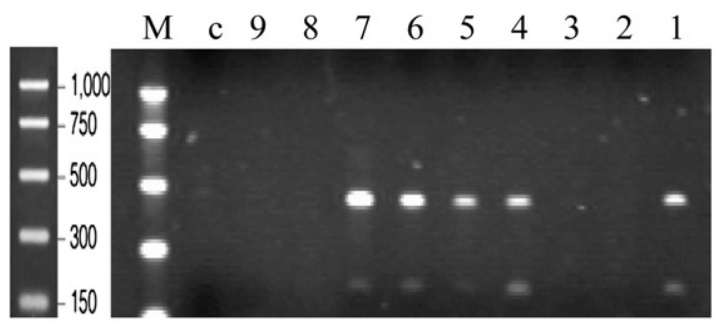

B $6 \mathrm{~h}$

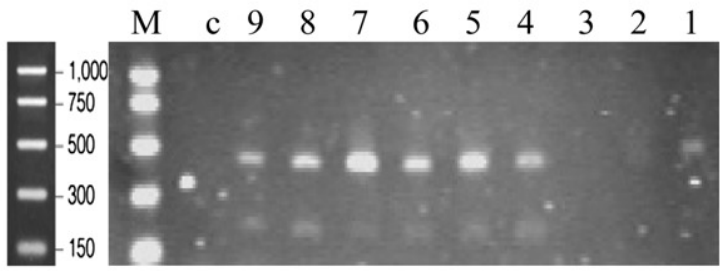

C $24 \mathrm{~h}$

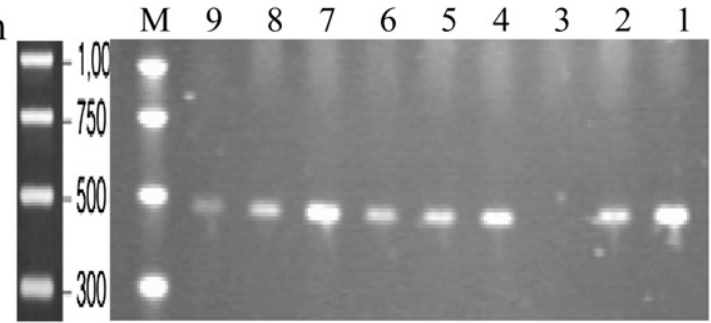

D $14 \mathrm{~d}$

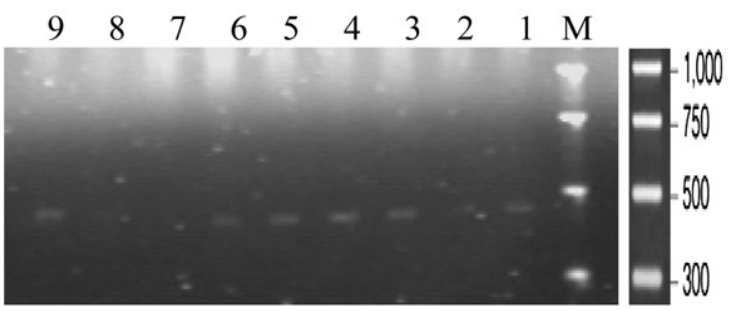

E

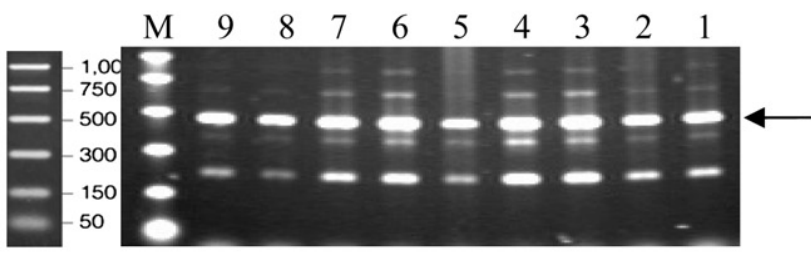

$\mathbf{F}$

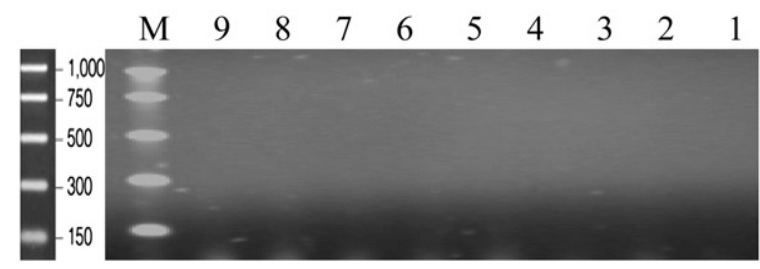

Fig. 2. RT-PCR products of cauliflower clones after $3 \mathrm{~h}(\mathrm{~A}), 6 \mathrm{~h}$ (B), $24 \mathrm{~h}$ (C), and $14 \mathrm{~d}$ (D) cold acclimation. The PCR product of genomic DNA (E) where the arrow indicates the bands of interest. RT-PCR under non-acclimation (F). $\mathrm{M}=$ Marker, lane $1=\mathrm{K} 1,2=\mathrm{K} 4$, $3=\mathrm{K} 9,4=\mathrm{K} 11,5=\mathrm{K} 13,6=\mathrm{K} 18,7=\mathrm{K} 19,8=\mathrm{K} 21,9=\mathrm{KC}$ (control).

\subsection{CBF expression and proline production under cold acclimation}

Cold acclimation increased proline production (Fig. 5A) and a significant positive correlation was found between CBF expression and proline production after $14 \mathrm{~d}$ cold acclimation (Fig. 5B) and no relationship was found under non-acclimation. 
$\mathbf{A}_{\text {Brop }}$

BrDREB1 114 TCGGAAGAagtTTCGGGAGACGCGTCACCCAATTTACAGAGGAGTACGTCTGAGAAACTC 173 BjDREB1B 121 TCGGAAGAAGTTCCGGGAGACGCGTCACCCAATTTACAGAGGAGTTCGTCTGAGAAACTC 180 BOCBF/DREB1 1 BnCBF5 298 TCGGAAGAATTTCGGGAGACGGTCACCCAATTTACAGAGGAGTTCGTCAGAGACACTC 357 Consensus
Con

BrDREB1 $174 \overline{\text { AGGTAAGTGGGTGTGTGAGGTAGGGAGCCAAACAAAAAGTCTAGGATTTGGCTCGGTAC }} 233$ BjDREB1B 181 AGGTAAGTGGGTGTGTGAAGTGAGGGAGCCAAACAAGAAATCTAGGATTTGGCTCGGTAC 240 BOCBF/DREB1 9 AGGTAAGTGGGTGTTGAGGTGAGAGAGCCAAACAAGAAATCCAGGATTTGGCTCGGTAC 68 BnCBF5 358 AGGTAAGTGGGTGGGGAGGTGAGAGAGCCAAACAAGAAATCCAGGATTTGGCTCGGAAC 417

Consensus $\quad * * * * * * * * * * * * * * * * * * * * * * * * * * * * * * * * * * * * * * * * * * * * * * * * * * * * * *$

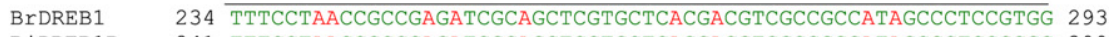
BjDREB1B 241 TTTCCTAACCGCCGAGATCGCAGCTCGTGCTCACGACGTCGCCGCCATAGCCCTCCGCGG 300 BOCBF/DREB1 69 TTTCCTAACCGCCGAGATCGCAGCTCGTGCTCACGACGTCGCCGCCATAGCCCTCCGTGG 128 BnCBF5 418 TTTCCTAACCGCCGAGATCGCAGCTCGTGCTCACGACGTCGCCGCCATAGCCCTCCGTGG 477 Consensus $\quad * * * * * * * * * * * * * * * * * * * * * * * * * * * * * * * * * * * * * * * * * * * * * * * * * * * * * * * * * \quad * *$

BrDREB1 294 CAAATCCGCCTGCCTCAATTTCGCCGACTCGGCTTGGCGGCTCCGTATCCCGGAGACAAC 353 BjDREB1B 301 CAAATCAGCTTGTCTCAATTTTGCTGACTCGGCTTGGCGGCTCCGTATCCCGGAGACAAC 360 $\begin{array}{lllll}\text { BjDREB1B } & 301 \text { CAAATCAGCTTGTCTCAATTTTGCTGACTCGGCTTGGCGGCTCCGTATCCCGGAGACAAC } & 360 \\ \text { BOCBF/DREB1 } 129 \text { CAAATCCGCCTGCCTCAATTTCGCCGACTCGGCTTGGCGGCTCCGTATCCCGGAGACAAC } & 188\end{array}$ $\begin{array}{llll}\text { BOCBF/DREB1 } & 129 & \text { CAAATCCGCCTGCCTCAATTTCGCCGACTCGGCTTGGCGGCTCCGTATCCCGGAGACAAC } & 188 \\ \text { BnCBF5 } & 478 \text { CAAATCCGCCTGCCTCAATTTCGCCGACTCGGCTTGGCGGCTCCGTATCCCGGAGAAAC } & 537\end{array}$ Consensus $\quad$ t

BrDREB1 354 ATGCCCCAAGGATATCCAGAAGGCGGCTGCTGAAGCCGCGGTGGCTTTTCAGGCTGAGAT 413 BjDREB1B 361 ATGCCCCAAGGAGATTCAGAAGGCGGCTGCTGAAGCCGCCTTGGCTTTTCAGGCTGAGAT 420 BOCBF/DREB1 189 ATGCCCCAAGGATATCCAGAAGGCGGCTGCTGAAGCCGCGGTGGCTTTTCAGGCTGAGAT 248 $\begin{array}{llll}\text { BOCBF/DREB1 } & 189 & \text { ATGCCCCAAGGATATCCAGAAGGCGGCTGCTGAAGCCGCGGTGGCTTTTCAGGCTGAGAT } & 248 \\ \text { BnCBF5 } & 538 \text { ATGCCCCAAGGATATCCAGAAGGGGCTGCTGAAGCCGCGGTGGCTTTTCAGGCTGAGAT } 597\end{array}$

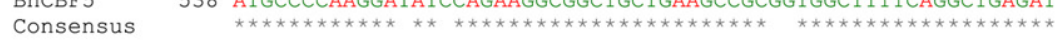

BrDREB1 414 AAATGATACGACGAAGGATCATGGCTTGGACGTGGAGGAGACGATCGTGGAGGCTATTTT 473 BjDREB1B 421 AAATAATACGACGACGGATCATGGCCTGGACATGGAGGAGACGATCGTGGAGGCTATTTT 480 BOCBF/DREB1 249 AAATGATACGACGACGGATCATGGCCTGGACGTGGAGGAGACGATCGTGGAGGCTATTTT 308 BnCBF5 598 AAATGATACGACGACGGATCATGGCCTGGACGTGGAGGAGACGATCGTGGAGGCTATTTT 657

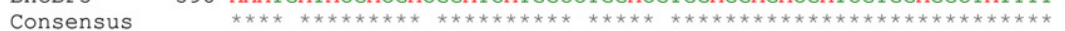

BrDREB1 474 TACGGAGGAAAACAGCGATGGGTTTTATATGGACGAGGAGGAGTCCATGTTCGGGATGCC 533 BjDREB1B 481 CACGGAGGAAAACAACGATGTGTTTTATATGGACGAGGAG---TCCATGTTAGAGATGCC 537 BOCBF/DREB1 309 TACGGAGGAAAACAACGATGGGTTTTATATGGACGAGGAGGAGTCCATGTTCGGGATGCC 368 BnCBF5 658 TACGGAGGAAACAACGATGGGTTTTATATGGACGAGGAGGAGTCCATGTTCGGGATGCC 717 Consensus $\quad * * * * * * * * * * * * * * * * * * * * * * * * * * * * * * * * * * * * * \quad * * * * * * * * * * * * * * *$

BrDREB1 534 GACCTTGTTGGCTAGCATGGCCGAAGGGATGCTTTTGCCGCCACCGTCCGTACAATTCGA 593 BjDREB1B 538 GGCCTTGTTGGCTAGTATGGCGGAAGAATGCTTTTGCCGCCGCCGTCCGTACATTTCGG 597 BOCBF/DREB1 369 GTCCTTGTTGGCTAGCATGGCGGAAGGTTGCCTTTTGCCATGCT------------ 412 BnCBF5 718 GTCCTTGTTGGCTAGCATGGCGGAAGGGATGCTTTTGCCGCCACCGTCGGTACGATTCGA 777 Consensus $\quad * * * * * * * * * * * * * * * * * * * * * * * * \quad * * * * * * * *$

B BnCBF5 MTSFSAFSEMMGSENESPA-LSGEYCPTLAASCPKKPAGRKKFRETRHPIYRGVRORHSG 59 BOCBF/DREB1 -

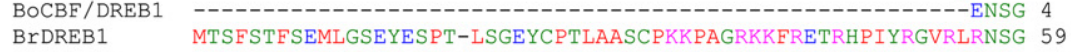
BjDREB1B MTSESTESEMLGSEYESPVTLGGEYCPTLAASCPKKPAGRKERETRHPIYRGVRLRNSG 60 Consensus

BACBF5 KWVCEVREPNKKSRIWLGTFLTAEIAARAHDVAAIALRGKSACLNFA DSAWRLRIPETTC 119 BOCBF/DREB1 KWVCEVREPNKKSRIWLGTFLTAEIAARAHDVAAIALRGKSACLNFADSAWRLRIPETTC 64 BIDREB1 KWVCEVREPNKKSRIWLGTFLTAEIAARAHDVAAIALRGKSACLNFADSAWRLRI PETTC 119 BjDREB1B KWVCEVREPNKKSRIWLGTFLTAEIAARAHDVAAIALRGKSACLNFADSAWRLRIPETTC 120

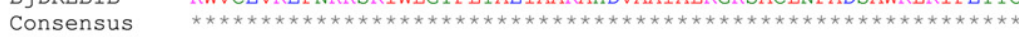

BnCBF5 PKDIQKAAAEAAVAFQAEINDTTTDHGLDVEETIVEAIFTEENNDGFYMDEEESMFGMPS 179 BOCBF/DREB1 PKDIOKAAAEAAVAFOAEINDTTTDHGLDVEETIVEAIFTEENNDGFYMDEEESMFGMPS 124 BrDREB1 PKDIQKAAAEAAVAFQAEINDTTKDHGLDVEETIVEAIFTEENSDGFYMDEEESMFGMPT 179 BjDREB1B PKEIQKAAAEAALAFQAEINNTTTDHGLDMEETIVEAIFTEENNDVFYMDEE-SMLEMPA 179

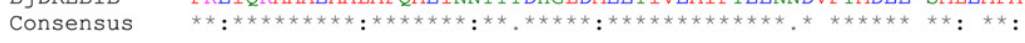

BnCBF5 LLASMAEGMLLPPPSVRFEHXYDFDGDAXVSLWSY 214

BOCBF/DREB1 LLASMAEGCLLPC-------------- 137

BRDREB1 LLASMAEGMLLPPPSVQFEYNYDFDGDTDVSLWSY 214

BjDREB1B LLASMAEGMLLPPPSVHFGHNYDFDGDADVSLWSY 214

Consensus $* * * * * * * * * * *$

Fig. 3. A. Nucleotide sequence (cDNA) of obtained putative CBF/DREB fraction from cauliflower and multiple sequence alignments with other Brassicas species. Alignments were made using ClustalW2 EMBL-EBI. Consensus symbols denoted as: "**" indicates that the nucleotides in that column are identical in all sequences in the alignment. ": indicates that conserved substitutions have been observed, “.” indicates that semi-conserved substitutions are observed. The AP2 region is indicated by the overline. BrDREB1 from Brassica rapa subsp. pekinensis, BjDREB1B from Brassica juncea, BoCBF/DREB1 sequence isolated from Brassica oleracea var. botrytis, BnCBF5 from Brassica napus. B. Multiple alignment and comparison of the deduced amino acids sequence of BoCBF/DREB1 with amino acid sequences of Brassica species. Brassica napus BnCBF5/DREB1 (GeneBank, AAM18958), Brassica juncea BjDREB1B (ABX00639), Brassica rapa subsp. pekinensis DREB1 (ACL12046), Bo. Brassica oleracea. The symbol “*” indicates the consensus and the DNA (CRT/DRE) binding AP2 domain is indicated by a thick overline. + indicates the CBF signature motif DSAWR and ":" indicates the conserved substitutions and "." indicates semi-conserved substitutions. The dotted line shows the missing amino acids of the full length gene sequence because of the isolation of only a partial sequence of the gene from $B$. oleracea var. botrytis. Percent consensus among the Brassica species was calculated and found to be $90 \%$ homology for 137 amino acids sequence of BoCBF/DREB1. The \% consensus calculated as the number of “*”/total amino acid sequence which is 123 aa and multiplied by $100=123 / 137 \times 100=90 \%$. C. Multiple alignment of the BoCBF/DREB1 deduced amino acids sequence with members of Brassicaceae family other than Brassica species. BoCBF/DREB1 (Brassica oleracea), Raphanus sativus RsCBF1 (ACX48435), Thlaspi arvense TaCBF (ABV82985), Eutrema salsugineum EsDREB1 (AAS00621) and Arabidopsis thaliana AtCBF2 (ABV27090). The symbol + indicates the CBF signature motif DSAWR, "**" indicates the identical amino acids in all sequences. ":" indicates conserved substitutions, "." indicates semi-conserved substitutions, the \% consensus was calculated as the number of "**/total amino acid sequence which is 137 aa and multiplied by $100=91 / 137 \times 100=67 \%$. 


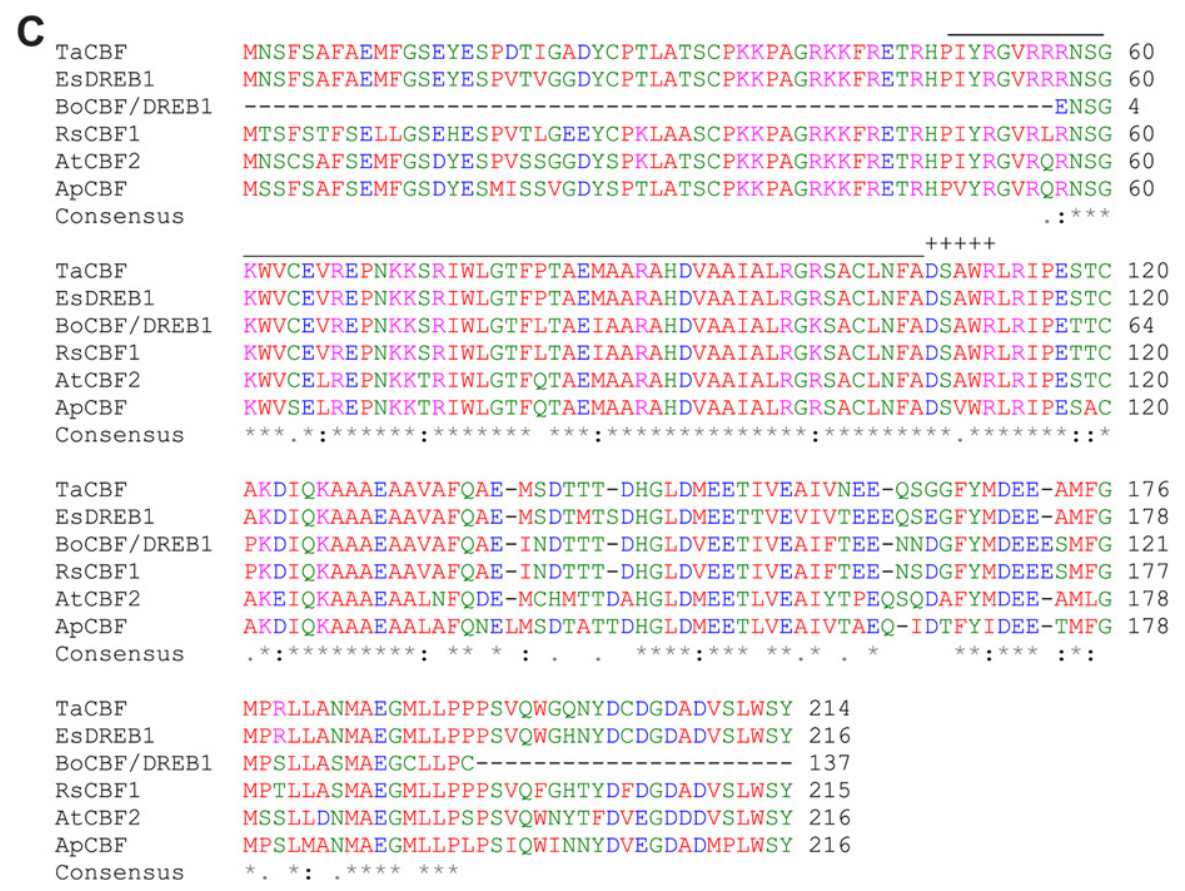

Fig. 3. (continued)

\subsection{Correlation between proline production and frost resistance}

There was a positive and significant correlation between proline content and frost resistance under cold acclimation at all of the tested freezing temperatures (Fig. 6A). Non-acclimated clones showed a very weak relationship between proline and frost resistance (Fig. 6B).

\subsection{Detection of COR15 gene}

The results of protein fractionation are presented in Fig. 7A. The Western blot results confirmed the presence of COR15 protein and this was repeated $2-3$ times to verify the results (Fig. 7B). The results clearly demonstrated the influence of cold acclimation on
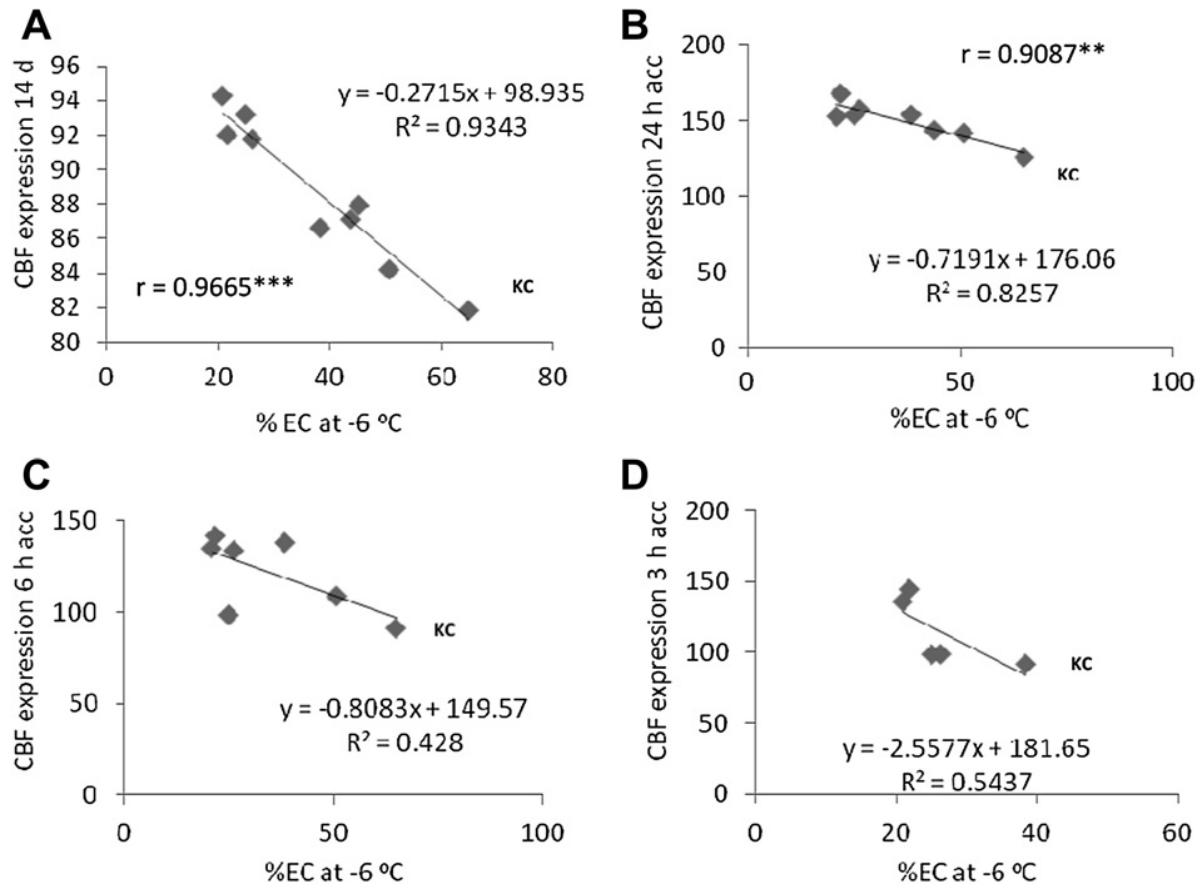

Fig. 4. Correlation between frost resistance (EC\% at $-6{ }^{\circ} \mathrm{C},-4{ }^{\circ} \mathrm{C}$ and $-2{ }^{\circ} \mathrm{C}$ ) and $\mathrm{CBF}$ expression after $14 \mathrm{~d}(\mathrm{~A}), 24 \mathrm{~h}(\mathrm{~B}), 6 \mathrm{~h}(\mathrm{C})$ and $3 \mathrm{~h}$ cold acclimation (D). The location of the control clone is indicated by KC. The data at $-6{ }^{\circ} \mathrm{C}$ temperature only is presented here because the other data at $-4{ }^{\circ} \mathrm{C}$ and $-2{ }^{\circ} \mathrm{C}$ also showed about similar correlation response, so to avoid figures repetition other data not presented. 
A

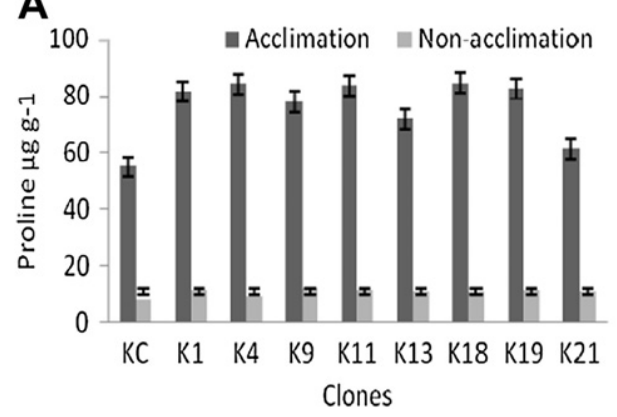

B

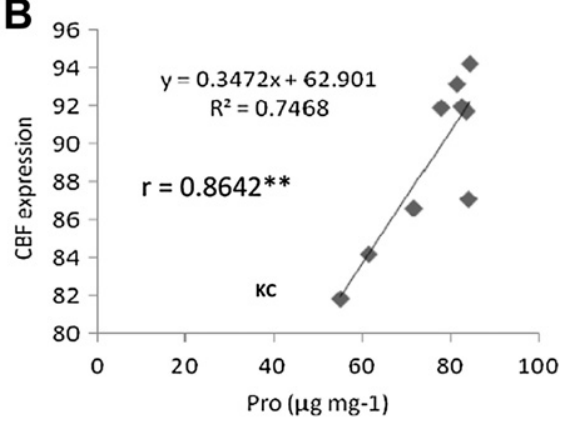

Fig. 5. (A) The effect of cold acclimation on proline production, KC (control) and K1-K21 (Mutants). The bars indicate the standard error of the mean of replicates. (B) Correlation between $\mathrm{CBF}$ expression and Proline production under cold acclimation. The location of the control clone is indicated by $\mathrm{KC}$.

the expression of COR15 and all the genotypes showed the presence of COR15 protein after $14 \mathrm{~d}$ acclimation (Fig. 7B). In non-acclimated conditions, mutants K1, K4 and K21 also showed clear blots while for other clones no blots were observed (Fig. 7C). This suggests constitutive expression of COR15 in these clones without cold acclimation. These three mutants also showed slightly higher frost resistance compared to other clones (K9, K11, K19, KC) under nonacclimation (Fig. 7D).

\section{Discussion}

In all the physiological tests there was no significant leakage of electrolytes from leaf discs treated at $-2{ }^{\circ} \mathrm{C}$, while there was a sharp increase in leakage at -4 and $-6{ }^{\circ} \mathrm{C}$. This suggests $B$. oleracea is resistant to $-2{ }^{\circ} \mathrm{C}$ but sensitive to freezing temperatures below this. Increased leakage of electrolytes reflects damage to cell membranes [26]. The physiological screening evidences could suggest that there might be a group of cold responsive genes in cauliflower induced under cold acclimation. The molecular evidences showed the identification and expression of BoCBF/ DREB1 and COR15 genes along with higher level of free proline under cold acclimation. The high resemblance ( $90 \%$ homology) of deduced amino acid sequence of BoCBF/DREB1 (Fig. 4A) with CBF from other species of Brassica suggests that the isolated sequence is highly conserved in Brassicas. These findings demonstrate the existence of some part of the CBF regulon pathway in cauliflower, as previously reported that $\mathrm{CBF}$ regulon includes COR genes, membrane stabilizing proteins and cryoprotectents such as proline [27]. The RT-PCR technique used in this investigation can be supported by previous scientists who had isolated cDNA sequences of CBF/DREB genes from other plants [28,29]. The cDNA sequences from both mutant and control clones were identical, that shows that in isolated part of gene sequence no mutation has occurred. Since there is evidence for differences in expression pattern then this suggests that the mutation might be in an upstream position or in a regulator gene like ICE (Inducer of CBF expression) a master switch of CBF genes regulation [30]. Further investigation is needed to explore the upstream DNA in this pathway for mutations in these mutants.

Cold acclimation increased frost resistance with expression of the BoCBF/DREB1 gene and the transcript level in mutants increased up to $24 \mathrm{~h}$ cold acclimation and then declined by $14 \mathrm{~d}$. Many scientists have reported a similar pattern of CBF/DREB1 expression [29,31-33]. Cold acclimation also induced frost resistance in control clones in comparison with non-acclimated conditions. This evidence showed that cold acclimation works to increase the frost resistance in cauliflower. The mutants showed highly frost resistance compared to the control clones under cold acclimation and even though the transcript of BoCBF/DREB1 appeared in control clones but very low when compared to the mutants. This evidence showed that mutagenesis has increased the level of expression of this gene, ultimately enhanced frost resistance in mutants. Similar effect of over-expressed CBF on frost tolerance has been reported $[15,34]$.

Proline was always produced in clones under both situations of either cold acclimation or non-acclimation but cold acclimation increased the proline level by about 8 fold and confirmed the previous findings of many researchers $[14,23,35]$. One reason here for the significant increase in proline level under cold acclimation might be the expression of BoCBF/DREB1 gene in mutants under cold acclimation because there was no transcript observed in nonacclimated clones. Gilmour [15] also reported increased proline production with over-expressed $\mathrm{CBF}$ gene. The increased proline and BoCBF/DREB1 transcript in mutants over control clones might

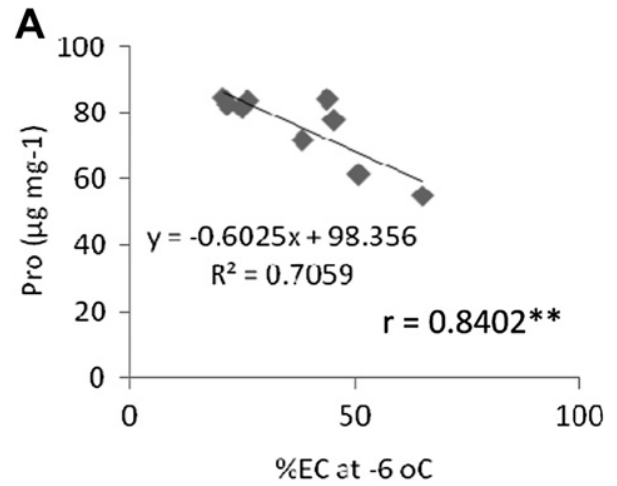

B

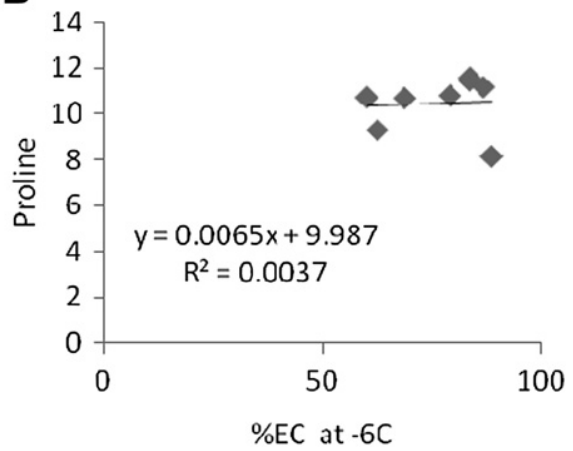

Fig. 6. Correlation between proline level and frost resistance (EC\% at $-6{ }^{\circ} \mathrm{C}$ ) under cold acclimation (A) and non-acclimation (B). 

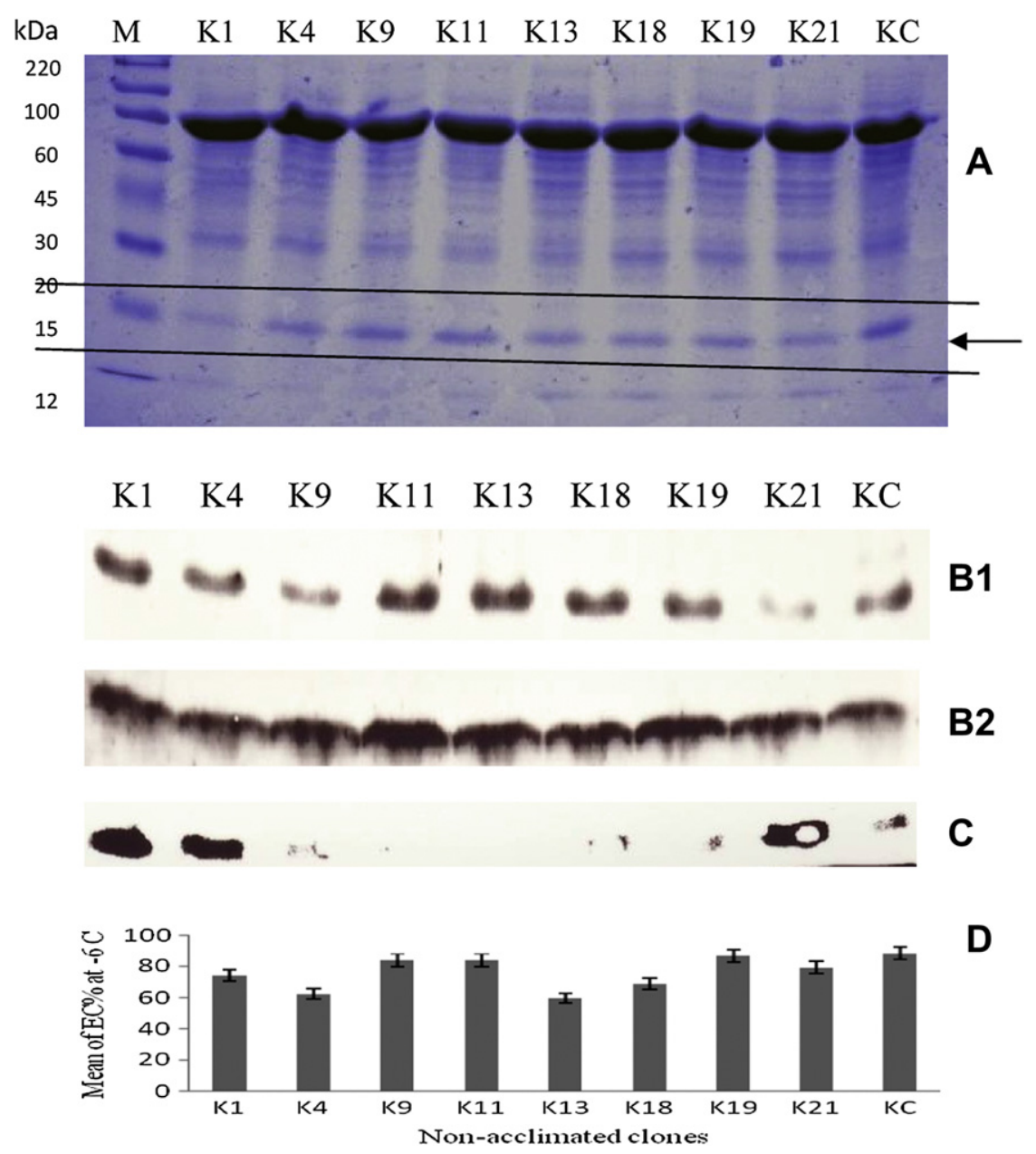

Fig. 7. (A) SDS-PAGE analysis, the arrow flanked by lines shows the band of interest. (B) Western blot of cold-acclimated clones for COR15 (B1 and B2 repeats for confirmation) (C) Western blot of non-acclimated clones for COR15. (D) Frost damage in non-acclimated clones (Electrical conductivity EC\%). M is marker proteins, K1-K21 are mutants and KC is control. The bars indicate the standard error of the mean of replicates.

be due to mutagenesis. The cold acclimation induced increase in proline level in correlation with frost tolerance can confirm the previous findings $[15,36]$. The mutants always showed higher proline level and frost resistance compared to control plants but the difference between mutants and control plants become very clear under cold acclimation. These findings demonstrated that the mutagenesis positively increased the proline level and subsequently enhanced frost resistance. Proline contributes to improved freezing tolerance in mutants over control plants [37].

All of the cold-acclimated clones expressed the COR15 gene, but under non-acclimation only in three mutants (K1, K4, K21) this gene expressed, that might indicate the presence of other transcription factors genes in cauliflower which induced the COR15 gene expression because in these mutants no RT-PCR bands appeared under non-acclimation. The frost resistance in coldacclimated clones where COR15 strongly expressed was slightly higher than non-acclimated clones. COR15 protein can reduce the susceptibility of membranes to freezing stress $[38,39]$. Other interesting thing observed here is the frost resistance level of mutants $\mathrm{K} 13$ and $\mathrm{K} 18$ which is about similar to K1, K4, and K21 under non-acclimation, while COR15 blots were not present for K13 and K18 under non-acclimation, that could suggests the presence of other genes and there might be some upstream mutation which might enhance the frost resistance in these mutants under nonacclimation. These results suggest further investigation to analyze these two mutants (K13 and K18). The appearance of the success of mutagenesis in this project confirmed that this is a promising method of producing mutant lines with better stress resistance in B. oleracea var. botrytis. Mutation breeding can have many advantages, such as multiple traits can be identified compared to transgenic approach where a single trait can be introduced in the crop, low cost, rapidity, simplicity and mutated varieties have more chances of survival in the environment [40]. Conclusively, the chemical induced mutagenesis and over expression of the identified BoCBF/DREB1 of cauliflower ( $B$. oleracea var. botrytis) is a promising approach to improve frost resistance.

\section{Materials and methods}

\subsection{Plant materials, mutagenesis and selection of stress resistant mutants}

Chemically induced mutants along with control (wild type) clones were maintained through sub-culturing under the in-vitro conditions in the Plant Physiology Lab, University of Plymouth UK. These mutants were assessed for their expression of stress resistance [23]. In the present investigation the highly frost resistant mutants were selected and transferred to greenhouse. The regeneration of clones was carried out from greenhouse and retransferred to in-vitro condition. Then the in-vivo grown clones in the 
greenhouse and the regenerated in-vitro clones were correlated for frost resistance for the confirmation of the induced resistance stability [41]. After regeneration these clones were symbolized as ' $\mathrm{K}$ ' in this paper and the highly frost resistant mutants (K1, K4, K9, $\mathrm{K} 11, \mathrm{~K} 13, \mathrm{~K} 18, \mathrm{~K} 19$, and $\mathrm{K} 21$ ) from the mutated population along with control clone $(\mathrm{KC})$ were subjected to molecular and biochemical investigations.

\subsection{Plant growth conditions}

The in-vitro clones were taken from the growth cabinet $\left(23^{\circ} \mathrm{C}\right.$ and $16 \mathrm{~h}$ photoperiod) and transferred to in-vivo conditions through a weaning process and then grown on in the glasshouse. Plants were then subjected to either cold-acclimating or nonacclimating conditions in Growth Cabinets. Acclimation conditions were $14 \mathrm{~d}$ at $4{ }^{\circ} \mathrm{C}, 8 \mathrm{~h}$ photoperiod, $180 \mu \mathrm{mol} \mathrm{m}{ }^{-2} \mathrm{~s}^{-1}$ light intensity and $75 \%$ humidity. Non-acclimation conditions were $22{ }^{\circ} \mathrm{C}, 16 \mathrm{~h}$ photoperiod $180 \mu \mathrm{mol} \mathrm{m}{ }^{-2} \mathrm{~s}^{-1}$ light intensity and $52 \%$ relative humidity.

\subsection{Analysis for frost tolerance}

Acclimated and non-acclimated plants were assessed for frost resistance using a leaf disc relative conductivity assay [22,23]. Ten leaf discs of $1 \mathrm{~cm}$ diameter each were cut from fully expanded photosynthetically active leaves and placed in boiling tubes. Three replicate tubes were used for each treatment for each clone. Total tubes used were $=9$ clones $\times 3$ replicates $\times 2$ unacclimated/ acclimated $\times 4$ different test temperatures ( 216 tubes). Three tubes without leaf discs (blanks) were used for monitoring EC contamination. The percent relative electrical conductivity was calculated as REC\% $=$ Post freezing EC/Post autoclaving EC $\times 100$. Tubes were held in the frost chamber in the dark at $+1{ }^{\circ} \mathrm{C}$ for $2 \mathrm{~h}$, ice added to each tube to initiate freezing, a sample taken, and the remainder then exposed to freezing to $-2,-4$, and $-6{ }^{\circ} \mathrm{C}$ with a hold of $2 \mathrm{~h}$ at each test temperature to ensure equilibration.

\subsection{RNA extraction}

Non-acclimated leaves were sampled after $14 \mathrm{~d}$ and cold-acclimated leaves sampled after $3 \mathrm{~h}, 6 \mathrm{~h}, 24 \mathrm{~h}$ and $14 \mathrm{~d}$ of cold acclimation. All samples were immediately frozen in liquid nitrogen to avoid RNA degradation. RNase cleaning agent (Sigma RNase ZAP cat \# R2020) was used for cleaning all surfaces before RNA isolation. The tissues were then ground in liquid nitrogen and $100 \mathrm{mg}$ of frozen tissue powder for each sample was weighed into $1.5 \mathrm{~mL}$ RNase free micro-centrifuge tubes (Ambion) and stored at $-80^{\circ} \mathrm{C}$ prior to RNA isolation. Leaf tissue samples $(100 \mathrm{mg})$ were taken from $-80^{\circ} \mathrm{C}$ and $500 \mu \mathrm{l}$ lyses solution (Sigma cat \# L8167) added and immediately vigorously vortexed for at least $30 \mathrm{~s}$ and then incubated at $56{ }^{\circ} \mathrm{C}$ for $5 \mathrm{~min}$. Total RNA was extracted from each clone using Sigma cat \# STRN50 and RNAlater ${ }^{\circledR}$ for RNA protection and the purified RNA in flow through eluate was distributed into small aliquots and stored at $-20^{\circ} \mathrm{C}$ for a short time and at $-80^{\circ} \mathrm{C}$ for long term storage.

\subsection{Identification of BoCBF/DREB1 gene}

Total RNA was used as the template for the synthesis of first strand cDNA using an ImProm-II ${ }^{\mathrm{TM}}$ Reverse Transcription (RT) System (Promega cat \# A3800). Each RNA sample (0.8 $\mu \mathrm{g} /$ reaction) was diluted with nuclease-free water (Sigma w1754) and primer oligos $(\mathrm{dT})_{15}(0.5 \mu \mathrm{g} /$ reaction $)$ were combined for a final volume of $5 \mu \mathrm{l} / \mathrm{RT}$ reaction in a $0.2 \mathrm{~mL}$ nuclease-free PCR tube (Ambion). A final volume of $20 \mu \mathrm{l}$ of RT mixture for each sample was prepared by combining $5 \mu \mathrm{l}$ of RNA + oligo (dT) $)_{15}$ primer mixture with $15 \mu \mathrm{l}$ RT reaction mixture. The first strand cDNA was synthesized in a thermal cycler (Perkin Elmer 9700) under the thermal cycle (Annealing: $25{ }^{\circ} \mathrm{C}$ for $5 \mathrm{~min}$, Extension: $42{ }^{\circ} \mathrm{C}$ for $60 \mathrm{~min}$, Inactivation of Reverse Transcriptase: $70^{\circ} \mathrm{C}$ for $15 \mathrm{~min}$ ). The amplification of first strand cDNA was made in a $50 \mu \mathrm{l} \mathrm{PCR} \mathrm{reaction} \mathrm{of} 25 \mu \mathrm{l} \mathrm{PCR}$ master mix $2 \times$ (Promega cat \# M7502), $5 \mu \mathrm{l}(10 \mu \mathrm{M})$ of each forward and backward primers, $5 \mu \mathrm{l}$ of first strand cDNA, and nuclease-free water (Sigma cat \# w1754) added to make $50 \mu \mathrm{l}$ of final reaction mixture for each sample. The gene specific (degenerate) forward and reverse primers (Forward, 5-AAGAAGTTT CGTGAGACCCGTCA C-3 and Reverse, 5-GGCAAAAGCATA CCTTC CGCCAT-3) were used. Initial denaturation at $94{ }^{\circ} \mathrm{C}$ for $3 \mathrm{~min}$ once, denaturation at $94{ }^{\circ} \mathrm{C}$ for $1 \mathrm{~min}$, annealing at $61^{\circ} \mathrm{C}$ for $1 \mathrm{~min}$, extension at $72^{\circ} \mathrm{C}$ for $2 \mathrm{~min}$ ( 35 cycles) and then a final extension at $72{ }^{\circ} \mathrm{C}$ for $10 \mathrm{~min}$ followed by $4{ }^{\circ} \mathrm{C} \infty$. The PCR products were run on a $0.8 \%$ high melting agarose (Sigma) gel and then visualized under UV light and photographs taken with a gel documentation system. The PCR products were compared with a PCR marker ladder (Promega cat \# G3161) and band intensities were semiquantitatively measured using Quantity one 4.6.3 Bio-Rad software.

\subsection{Sequence analysis and multiple alignments}

The cDNA fragment was excised in a minimum volume of agarose gel using a clean sharp scalpel. Each slice was then transferred to a $1.5 \mathrm{~mL}$ micro-centrifuge tube (Ambion) and isolation of the DNA fragment was carried out using the ${ }^{\circledR}$ SV Gel and PCR Clean-Up System (Promega A9281). The weight of the tube was noted before and after addition of the slice. Membrane binding solution was added to the tube at a ratio of $10 \mu \mathrm{l} / 10 \mathrm{mg}$ of agarose gel slice, mixed very gently and incubated at $61{ }^{\circ} \mathrm{C}$ until the gel slice dissolved completely. This was centrifuged briefly at room temperature and DNA was purified with an SV mini-column and the purified DNA was subjected to sequencing (Eurofins MWG Operon, Germany). Some of the purified DNA was stored at $4{ }^{\circ} \mathrm{C}$ for a short time and at $-20^{\circ} \mathrm{C}$ for longer storage. Multiple sequence alignments of the deduced amino acid sequence of the isolated gene with other cold induced genes sequences were carried out using ClustalW2. EMBL-EBI [24] and BLAST (NCBI).

\subsection{Genomic DNA isolation}

Leaves from each clone were ground into a fine powder in liquid nitrogen, using a mortar and pestle, and $100 \mathrm{mg}$ of the powder transferred to a $1.5 \mathrm{~mL}$ micro-centrifuge tube (Ambion) on ice and $350 \mu \mathrm{l}$ lyses solution A and $50 \mu \mathrm{l}$ of lyses solution B were added and isolation of DNA was carried out (Sigma G2N10).

\subsection{Proline extraction and estimation}

Free proline was extracted from leaf frozen powders stored at $-80{ }^{\circ} \mathrm{C}$ following the method of Bates [42]. Samples of $100 \mathrm{mg}$ were homogenized in $1.5 \mathrm{~mL}$ of $3 \%$ sulfosalicylic acid in $2 \mathrm{~mL}$ tubes and centrifuged at $13,000 \times \mathrm{g}$ for $5 \mathrm{~min}$ at room temperature. $300 \mu \mathrm{l}$ of the supernatant was incubated for $1 \mathrm{~h}$ with $2 \mathrm{~mL}$ glacial acetic acid and $2 \mathrm{~mL}$ acid ninhydrin in test tubes at $100^{\circ} \mathrm{C}$ in a water bath. The tubes were then immediately dipped in ice. The reaction mixture was extracted with $1 \mathrm{~mL}$ toluene by mixing vigorously for 10-30 s. The chromophore containing toluene was pipetted into a fresh tube, warmed to room temperature and its absorbance noted at $520 \mathrm{~nm}$ by spectrophotometer using toluene as a blank. The proline concentration in samples was determined from a predetermined standard curve. The reaction for each sample was performed in triplicate. 


\subsection{Protein extraction and Western blotting}

Leaf tissues from $-80^{\circ} \mathrm{C}$ were thawed on ice, placed in a mortar and pestle and $2 \mathrm{~mL}$ extraction buffer [43] (100 mM potassium phosphate, $1 \mathrm{mM}$ DTT, $1 \mathrm{mM}$ EDTA, 1\% Triton X-100, 10\% glycerol, $\mathrm{pH} 7.8$ ) was added to $1 \mathrm{~g}$ of tissues and ground. $1 \mathrm{~mL}$ of the liquid grindate was transferred to a microfuge tube $(1.5 \mathrm{~mL})$ on ice. The supernatant was centrifuged twice at $13,000 \times \mathrm{g}$ for 15 and $10 \mathrm{~min}$ respectively at $4{ }^{\circ} \mathrm{C}$. The clear supernatant containing proteins was separated using SDS-PAGE (Sodium dodecyl sulfate polyacrylamide gel electrophoresis) [44] and visualized using Coomassie blue staining solution. Unstained gels were used for Western blotting and the proteins were transferred to a nitrocellulose membrane by electro-blotting at $15 \mathrm{~V}$ for $90 \mathrm{~min}$. One liter of $1 \times$ Tris-glycine transfer buffer was prepared by dissolving Tris- $\mathrm{HCl} 3.05 \mathrm{~g}$, Glycine $14.4 \mathrm{~g}$, adding methanol $200 \mathrm{~mL}, \mathrm{ddH}_{2} \mathrm{O} 800 \mathrm{~mL}, \mathrm{pH} 8.3$ adjusted with $\mathrm{NaOH}$ [45]. After transferring the proteins onto the nitrocellulose membrane, the membrane was incubated in blocking solution (PBST $+2 \% \mathrm{BSA}$ ) for $1 \mathrm{~h}$ at room temperature with mild shaking. After incubation, the membrane was washed with PBST twice for 5 min each, followed by incubation with primary COR15 antibodies obtained from the Lab of the Dr. Michael Thomashow (MSU, USA). Primary antibodies were diluted (1:1000) in a total volume of $20 \mathrm{~mL}$ PBST and the membrane was incubated at room temperature overnight with very mild shaking. The membranes were then washed 3 times with PBS while agitating, for 10 min each and the membrane then incubated in goat anti rabbit IgG horseradish peroxidase conjugated secondary antibody (PBS diluted $1: 20,000$ ) (Abcam) for $90 \mathrm{~min}$ at room temperature with mild shaking to detect primary antibodies attached to the COR15 protein. The membranes were washed 3 times with PBS for $10 \mathrm{~min}$ each and then incubated in developmental solution (DAB $0.06 \mathrm{~g}$, $\mathrm{NiCl}_{2} 0.03 \mathrm{~g}$ in $100 \mathrm{~mL}$ PBST) for about $15 \mathrm{~min}$. The membranes were washed repeatedly with PBS, and blots were observed and digital images made.

\subsection{Statistical analysis}

Analysis of variances (ANOVA) was performed using Minitab 15 and correlation among the different parameters was investigated using Microsoft Excel and values of the correlation coefficient for different levels of significance investigated according to Fisher and Frank [46].

\section{Acknowledgments}

The authors are grateful to Dr. Michael Thomashow and Dr. Sarah Gilmour of Michigan State University (USA) for providing the antibodies for the COR15a protein. The first author would like to acknowledge the Pakistan Higher Education Commission (HEC) and the University of Malakand for the award of the scholarship that provided the financial support for this research project.

\section{References}

[1] M. Shilpi, T. Narendra, Cold, salinity and drought stresses: an overview, Arch. Biochem. Biophys. 444 (2005) 139-158.

[2] M.F. Thomashow, Plant cold acclimation, freezing tolerance genes and regulatory mechanisms, Annu. Rev. Plant Physiol. Plant Mol. Biol. 50 (1999) 571-599.

[3] S. Mantas, H. Pekka, P.E. Tapio, Genes and gene regulation for low temperature tolerance. in: A.J. Mathew, J.W. Andrew (Eds.), Genes for Plant Abiotic Stress. Willey-Blackwell Publishing, 2010, pp. 187-209.

[4] D.K. Hincha, U. Heber, J.M. Schmitt, Freezing ruptures thylakoid membranes in leaves, and rupture can be prevented in vitro by cryoprotective proteins, Plant Physiol. Biochem. 27 (1989) 795-801.
[5] M.C. Gamboa, S. Rasmussen-Poblete, D.T. Pablo, E.K. Valenzuela, Isolation and characterization of a cDNA encoding a CBF transcription factor from E. globules, Plant Physiol. Biochem. 45 (2007) 1-5.

[6] S.S. Baker, K.S. Wilhelm, M.F. Thomashow, The 59-region of Arabidopsis thaliana cor15a has cis- acting elements that confer cold-, drought- and ABAregulated gene expression, Plant Mol. Biol. 24 (1994) 701-713.

[7] E.J. Stockinger, S.J. Gilmour, M.F. Thomashow, Arabidopsis thaliana CBF1 encodes an AP2 domain containing transcriptional activator that binds to the C-repeat/DRE, a cisacting DNA regulatory element that stimulates transcription in response to low temperature and water deficit, Proc. Natl. Acad. Sci. U S A 94 (1997) 1035-1040.

[8] K.R. Jaglo, S. Kleff, K.L. Amundsen, X. Zhang, V. Haake, J.Z. Zhang, T. Deits, M.F. Thomashow, Components of the Arabidopsis C-repeat/dehydrationresponsive element binding factor cold-response pathway are conserved in Brassica napus and other plant species, Plant Physiol. 127 (2001) 910-917.

[9] K.R. Jaglo, S.J. Gilmour, D.G. Zarka, O. Schabenberger, M.F. Thomashow, Arabidopsis CBF1 over-expression induces COR genes and enhances freezing tolerance, Science 280 (1998) 104-106.

[10] I.M. Wieslawa, S.W. Eve, Regulon organization of Arabidopsis, BMC Plant Biol. 8 (2008) $1-22$

[11] Z. Chunzhen, F. Shui-zhang, W. Scott, L. Lijia, H. David, Identification of genes associated with cold acclimation in perennial ryegrass, J. Plant Physiol. 166 (2009) 1436-1445.

[12] J.D. Ashton, P.S. Desh, Proline biosynthesis and osmoregulation in plants, Plant J. 4 (1993) 215-223.

[13] A.R. Kemble, H.T. MacPherson, Liberation of amino acids in perennial rye grass during wilting, Biochem. J. 58 (1954) 46-59.

[14] L.A. Wanner, O. Junttila, Cold-induced freezing tolerance in Arabidopsis, Plant Physiol. 120 (1999) 391-400.

[15] S.J. Gilmour, A.M. Sebolt, J.D. Everard, M.F. Thomashow, Over expression of the Arabidopsis CBF3 transcriptional activator mimics multiple biochemical changes associated with cold acclimation, Plant Physiol. 124 (2000) 1854-1865.

[16] I.B. Nonnecke, Vegetable Production. Van Nostrand Reinhold Co, New York, USA, 1989.

[17] H.C. Thompson, W.C. Kelly, Vegetable Crops. Mc Graw-Hill Book Co, USA, 1957.

[18] S. Tossaint, History of Food. Blackwell Publishing, USA, 1994.

[19] W.B. Christopher, Cancer preventive properties of varieties of Brassica oleracea: a review, Am. J. Clin. Nutr. 59 (1994) 166-170.

[20] K. Robert, Nutrition and the Musician, 2001 Healthcare Supplement Allegro No. 5 (2001).

[21] U. N., Genome analysis in Brassica with special reference to the experimental formation of B. napus and peculiar mode of fertilization, Jap. J. Bot. 7 (1935) 389-452.

[22] M.P. Fuller, M. Eed, The development of multiple stress-resistance cauliflower using mutagenesis in conjunction with a microshoot tissue culture technique, Acta Hortic. 618 (2003) 71-76.

[23] M.P. Fuller, E.M. Metwali, M.H. Eed, A.J. Jellings, Evaluation of abiotic stress resistance in mutated populations of cauliflower (Brassica oleracea var. botrytis), Plant Cell Tissue Organ Cult. 86 (2006) 239-248.

[24] M.A. Larkin, G. Blackshields, N.P. Brown, R. Chenna, P.A. McGettigan, H. McWilliam, F. Valentin, I.M. Wallace, A. Wilm, R. Lopez, J.D. Thompson, T.J. Gibson, D.G. Higgins, ClustalW and ClustalX version 2, Bioinformatics 23 (2007) 2947-2948.

[25] Y. Sakuma, Q. Liu, J.G. Dubouzet, H. Abe, K. Shinozaki, K. Yamaguchi-Shinozaki, DNA-binding specificity of the ERF/AP2 domain of Arabidopsis DREBs, transcription factors involved in dehydration- and cold-inducible gene expression, Biochem. Biophys. Res. Commun. 290 (2002) 998-1009.

[26] A. Srinivisan, H. Takeda, T. Senboku, Heat tolerance in food legume as evaluated by cell membrane thermostability and chlorophyll florescence technique, Euphytica 88 (1996) 35-40.

[27] M.F. Thomashow, So what's new in the field of plant cold acclimation? Lots, Plant Physiol. 125 (2001) 89-93.

[28] S. Kume, F. Kobayashi, M. Ishibashi, R. Ohno, C. Nakamura, S. Takumi, Differential and coordinated expression of $\mathrm{Cbf}$ and $\mathrm{Cor} /$ Lea genes during longterm cold acclimation in two wheat cultivars showing distinct levels of freezing tolerance, Genes Genet. Syst. 80 (2005) 185-197.

[29] Z. Yong, Y. Tong-Wen, Z. Li-Jing, Z. Teng-Guo, D. Cui-Xia, X. Shi-Jian, A. Li-Zhe, Isolation and expression analysis of two cold-inducible genes encoding putative CBF transcription factors from Chinese cabbage (Brassica pekinensis Rupr.), JIPB 48 (2006) 848-856.

[30] H.A. VanBuskirk, M.F. Thomashow, Arabidopsis transcription factors regulating cold acclimation, Physiol. Plant. 126 (2006) 72-80.

[31] X. Huogen, E.A. Tattersall, K.S. Mahbuba, R.C. Grant, N. Annette, CBF4 is a unique member of the CBF transcription factor family of Vitis vinifera and Vitis riparia, Plant Cell Environ. 31 (2008) 1-10.

[32] L. Cong, T.Y. Chai, Y.X. Zhang, Characterization of the novel gene BjDREB1B encoding a DRE-binding transcription factor from Brassica juncea, Biochem. Biophys. Res. Commun. 371 (2008) 702-706.

[33] F. Novillo, J.M. Alonso, J.R. Ecker, J. Salinas, CBF2/DREB1C is a negative regulator of CBF1/DREB1B and CBF3/DREB1A expression and plays a central role in stress tolerance in Arabidopsis, Proc. Natl. Acad. Sci. U S A 101 (2004) 3985-3990. 
[34] M. Wisniewskim, J. Norelli, C. Bassett, T. Artlip, D. Macarisin, Ectopic expression of a novel peach (Prunus persica) CBF transcription factor in apple (Malus 3 domestica) results in short-day induced dormancy and increased cold hardiness, Planta (2010). doi:10.1007/s00425-011-1358-3.

[35] K.K. Koster, D.V. Lynch, Solute accumulation and compartmentation during the cold acclimation of puma rye, Plant Physiol. Biochem. 98 (1992) 108-113.

[36] A.N. Misra, A.K. Biswal, M. Misra, Physiological, biochemical and molecula aspects of water stress in plants, and their biotechnological applications, Proc. Natl. Acad. Sci. U S A 72 (2002) 115-134.

[37] Z. Xin, J. Browse, eskimo1 mutants of Arabidopsis are constitutively freezingtolerant, Proc. Natl. Acad. Sci. U S A 95 (1998) 7799-7804.

[38] N.N. Artus, M. Uemura, P.L. Steponkus, S.J. Gilmour, C. Lin, M.F. Thomashow, Constitutive expression of the cold-regulated Arabidopsis thaliana COR15a gene affects both chloroplast and protoplast freezing tolerance, Proc. Natl. Acad. Sci. U S A 93 (1996) 13404-13409.

[39] J.J. Polashock, R. Arora, Y. Peng, N. Dhananjay, L.J. Rowland, Functional identification of a blueberry CBF/DREB-like element associated with cold acclimation and freezing tolerance, J. Am. Soc. Hortic. Sci. 35 (2010) 40-48.
[40] J.S. Mohan, Mutagenesis in crop improvement under the climate change, Rom. Biotechnol. Lett. 15 (2010) 88-106.

[41] F. Hadi, M.P. Fuller, Enhanced tolerance to abiotic stress in cauliflower by mutagenesis, Proc. Intern. Conf. Plant Abiotic Stress Tolerance, 08-11 Feb. Austria, Vienna, 2009. p. 168.

[42] L.S. Bates, R.P. Waldren, I.O. Teare, Rapid determination of free proline for water stress studies, Plant Soil 19 (1973) 205-207.

[43] M. Ni, K. Dehesh, J.M. Tepperman, P.H. Quai, GT-2: in-vivo transcriptional activation activity and definition of novel twin DNA binding domains with reciprocal target sequence selectivity, Plant Cell 8 (1996) 1041-1059.

[44] U.K. Laemmli, Cleavage of structural proteins during the assembly of the head of bacteriophage T4, Nature 227 (1970) 680-685.

[45] H. Towbin, T. Staehelin, J. Gordon, Electrophoretic transfer of proteins from polyacrylamide gels to nitrocellulose sheets: procedure and some applications, Proc. Natl. Acad. Sci. U S A 76 (1979) 4350-4354.

[46] R.A. Fisher, Y. Frank, Statistical Tables for Biological, Agricultural and Medical Research, third ed. Oliver and Boyd, 98 Great Russel Street, W.C. Edinburgh Tweeddale Court, London, 1948. 